\title{
Intersimple Sequence Repeats Distinguish Genetic Differences in Easter Lily 'Nellie White' Clonal Ramets within and among Bulb Growers over Years
}

\author{
Neil O. Anderson ${ }^{3,4}$ \\ Department of Horticultural Science, University of Minnesota, 1970 Folwell Avenue, St. Paul, MN \\ 55108
}

\author{
Adnan Younis ${ }^{1}$ \\ Department of Horticultural Science, University of Minnesota, 1970 Folwell Avenue, St. Paul, MN \\ 55108; and Institute of Horticultural Sciences, University of Agriculture, Faisalabad, 38040 Pakistan
}

Ye Sun ${ }^{2}$

Department of Plant Biology, University of Minnesota, 250 Biological Science Center, 1445 Gortner Avenue, St. Paul, MN 55108

\begin{abstract}
AdDitional INDEX WORDS. genetic variation, intraclonal selection, Lilium longiflorum, Muller's ratchet, mutation, ortet
ABstract. The large genome size of easter lily [Lilium longiflorum (77.1 pg/2C nucleus)], coupled with repetitive DNA sequences, makes it difficult to use molecular techniques to identify or fingerprint lily (Lilium) species, hybrids, and clones. Previous research demonstrated that amplified fragment length polymorphisms could not be optimized for consistency and repeatability to obtain reliable genetic variation assessments of lily species and clones. The objective of this research was to analyze the effectiveness and stringency of intersimple sequence repeats (ISSRs) to determine genetic differences between $L$. longiflorum 'Nellie White' clonal ramet populations from bulb growers over years. DNA from closely related clones of $L$. longiflorum 'Nellie White' included 2002 ( $n=11$ bulb lots) and 2003 ( $n=12$ bulb lots). Comparison cultivars and species were also included. Five University of British Columbia (UBC) primers (P808, P810, P811, P814, and P818) that were used produced 56 polymorphic loci. ISSR banding patterns were consistent among three replications within 'Nellie White' clonal genotypes. 'Nellie White' clones differed significantly within $(82 \%)$ and among (18\%) growers in 2002 and 2003. 'Nellie White' clones are not uniform or part of a single ramet population. Principal clades within years separated at Nei's genetic distances (GDs) of GD $=0.6$ (growers 2, 4, and 12) to $\mathrm{GD}=\mathbf{0 . 8 2}$ (grower 6) in 2002 and GD $=\mathbf{0 . 5 1}$ (grower 4) to $\mathbf{G D}=\mathbf{0 . 7 8}$ (grower 14). The most closely related 'Nellie White' clones within growers ranged from $\mathrm{GD}=0.8$ to 0.95 in 2002 and $\mathrm{GD}=0.7$ to 0.91 for 2003 . Five top-performing growers (1, and 3-6) from previous morphological studies and, particularly growers 3 and 5, were in similar clades, cosegregating with phenotypic traits of stem emergence and flowering dates. The lack of a meiotic sieve (Muller's ratchet) may be responsible for the high level of mutational differences present in the 'Nellie White' clones and significantly affects the ability of commercial greenhouse growers to produce a uniform easter lily crop, particularly in years when the Easter holiday is early.
\end{abstract}

Lilium contains $\approx 100$ species across the Northern Hemisphere between $10.00^{\circ} \mathrm{N}$ and $60.00^{\circ} \mathrm{N}$. lat. (Anderson, 1986; Asano, 1986, 1989; De Jong, 1974). Many species are important commercial floricultural crops for use as flowering potted plants, cut flowers, and garden perennials (Dole and Wilkins, 2005). Of these, easter lily ranks among the top five potted flowering plants in sales for the United States (U.S. Department of Agriculture, 2009). The primary easter lily cultivar in North America is L. longiflorum 'Nellie White', a vegetatively propagated clone that is $>60$ years old (Zlesak and Anderson, 2003,

\footnotetext{
Received for publication 5 Jan. 2010. Accepted for publication 26 July 2010. This research was supported by the Minnesota Agricultural Experiment Station, by grants from the Fred C. Gloeckner Company, by the North Star Lily Society of Minnesota, and by the Higher Education Commission, Islamabad, Pakistan. We thank Ollie Hoffman, Lee Riddle, and the Easter Lily Research Foundation for collecting germplasm used in this study.

${ }^{1}$ Visiting Postdoctoral Research Fellow, University of Minnesota; Assistant Professor, University of Agriculture, Pakistan.

${ }^{2} \mathrm{Ph}$.D. Graduate Research Assistant, Plant Biological Sciences Graduate Program. ${ }^{3}$ Associate Professor.

${ }^{4}$ Corresponding author. E-mail: ander044@umn.edu.
}

2007). A lily bulb grower, J. White, named 'Nellie White' after his wife (Texas A\&M University, n.d.). The original seedling may have originated from crosses performed at Colorado State University (D. Hartley, personal communication).

Easter lily is the only major floral crop that is propagated independently by each of the $\approx 12$ bulb growers in the Pacific Bulb Growers' Association (Zlesak et al., 2007). Four to five of these 12 growers supply $75 \%$ of the 'Nellie White' clones for the market (Zlesak, 2006). Each bulb grower selects and propagates their own 'Nellie White' variants as a result of periodic screens of new, favorable lines (Zlesak and Anderson, 2003). This has the potential to allow for differing 'Nellie White' intraclonal mutational lines (ramets) to be selected, propagated, and produced by each wholesale bulb grower. Continuous asexual propagation of 'Nellie White' without periodic sexual cycles and meiotic purging of deleterious recessive alleles has allowed for operation of Muller's ratchet (Anderson and Ascher, 1994; Muller, 1964). This has led to significant clonal decline [increases in sterility, lily symptomless virus titer (Anderson and Ascher, 1994; Zlesak and Anderson, 2007)]. Previous widely used easter lily clones (e.g., 'Croft' and 'Ace') 
also experienced clonal decline and were dropped from production (Zlesak and Anderson, 2003).

The potential for mutations within 'Nellie White' due to clonal propagation allows for morphological variation to surface in the clone (Veilleux and Johnson, 1998). This has often been dismissed with the assertion that most variation is caused by environmental factors rather than genetic ones (Fisher and Lieth, 2000). Environmental factors, such as the bulb grower's field conditions, have caused greenhouse bulb forcers to routinely purchase from at least two bulb growers annually to minimize wide forcing variation for early Easter dates (Zlesak and Anderson, 2003). Populations of 'Nellie White' exhibited variability in days to stem emergence, visible flower bud, flower anthesis, plant and inflorescence height and number of leaves, bulb weight and circumference, and number of stems and flowers (Zlesak and Anderson, 2007). While the 'Nellie White' phenotype varied widely between bulb growers within years (2002 and 2003), this variation did not disappear when the environmental component was standardized in subsequent forcing cycles (Zlesak and Anderson, 2007). Thus, it would appear that a significant portion of the 'Nellie White' phenotypic variation may also arise from the genetic component because, by definition, phenotype $=$ genotype $\times$ environment $(\mathrm{G} \times \mathrm{E})$.

Objectively determining genetic variability in asexual crops (i.e., easter lily) can be performed irrespective of environmental variation, such as bulb growers' field conditions (Veilleux and Johnson, 1998). Many protein and molecular DNA techniques are available for such research endeavors (Beckman and Soller, 1986). Polymorphisms of bulb scale proteins using isoelectric focusing have been used in Lilium for cultivar identification (Booy et al., 1998). Randomly amplified polymorphic DNA (RAPD) markers have been successfully used to detect genetic variation in many horticultural species and clonal cultivars; for example, in Camellia (Devarumath et al., 2002), Rosa (Debener et al., 1996; Torres et al., 1993), Lilium (Dai et al., 2007; Lee et al., 1993; Persson et al., 1998), and Scaevola (Swoboda and Bhalla, 1997). RAPD markers were used to infer phylogenetic relations and resolve paternity issues in wide hybrid lily crosses (Wen and Hsiao, 2001; Yamagishi, 1995). RAPDs, however, are often not reproducible or may lack sufficient markers and limit inferences about closely related clonal ramets (Yamagishi, 1995).

Polymerase chain reaction (PCR)-based approaches are more commonly used due to their simplicity, requiring only small DNA quantities (Devarumath et al., 2002). Intersimple sequence repeats (ISSRs) or intermicrosatellites are arbitrary multiloci markers produced by PCR amplification with a microsatellite primer. ISSR markers exhibit high polymorphism due to variability in the number of tandem repeats present in these sequences (Levinson and Gutman, 1987). ISSR fingerprinting is more reproducible than RAPD amplification due to the longer SSR-based primers, thus enabling higher-stringency DNA amplifications (Williams et al., 1990). It is a powerful tool for investigating genetic variation of closely related individuals that exhibit low levels of polymorphism (Godwin et al., 1997; Hale et al., 2005; Zietkiewicz et al., 1994). ISSRs have been used in fingerprinting and genetic analyses of several horticultural crops [e.g., Olea europaea (Hess et al., 2000), Magnifera indica (Liu et al., 2007), Chrysanthemum (Wolff et al., 1995), Leucadendron (Pharmawati et al., 2005), asiatic Lilium (Abe et al., 2002; Yamagishi et al., 2002), L. longiflorum hybrids (Wang et al., 2009), and interspecific $($ L. $\times$ formolongi $) \times L$. martagon hybrids (Anderson et al., 2009)].
ISSRs have also been used in the construction of genetic maps (Wu and Tanksley, 1993) and to detect clonal diversity by fingerprinting closely related genotypes (Camacho and Liston, 2001; Esselman et al., 1999; Mayes et al., 1998; Rongwen et al., 1995; Zietkiewicz et al., 1994). The hypervariability of ISSR markers enables small differences to be detected, even at the subspecies level (Wolfe et al., 1998). ISSRs were used to detect subtle somaclonal differences in asexually propagated Camellia (Devarumath et al., 2002) and Phalaris (Gyulai et al., 2003). In Camellia, ISSRs detected $8.5 \%$ more polymorphic loci than did RAPDs (Devarumath et al., 2002).

Amplified fragment length polymorphisms (AFLPs) are random, robust genome-wide markers providing high sensitivity with many polymorphic markers : primer pair (Ridout and Donini, 1999; Vos et al., 1995). Highly repetitive DNA sequences or large genome sizes frequently inhibit the use of AFLPs (Fay et al., 2005). Such has proven to be the case in $L$. longiflorum with its $77.1 \mathrm{pg} / 2 \mathrm{C}$ nucleus (Lim et al., 2001), a genome $\approx 550 \times$ that of Arabidopsis thaliana (Bennett et al., 1982). Lilium henryii was found to contain $>13,000$ copies of a single retrotransposon (Smyth et al., 1989). As a result, Zlesak et al. (2007) could not use AFLPs to detect clonal differences of L. longiflorum 'Nellie White' due to a lack of repeatability and consistency for scorable bands. Thus, AFLPs cannot be used to assess genetic variability and clonal integrity in L. longiflorum. The objective of this study was to employ ISSRs to determine whether genetic differences exist between clonal ramets of $L$. longiflorum 'Nellie White' [obtained from the easter lily bulb growers and the Easter Lily Foundation (Brookings, OR) in 2002 and 2003] used in morphological (Zlesak and Anderson, 2007) and AFLP studies (Zlesak et al., 2007).

\section{Materials and Methods}

DNA samples of most L. longiflorum 'Nellie White' genotypes previously analyzed for morphological variation in two forcing cycles (Zlesak and Anderson, 2007) and AFLP analyses (Zlesak et al., 2007) were available for this study (Table 1). A total of 144 (2002) and 165 (2003) 'Nellie White' genotypes, and comparison genotypes of L. longiflorum 'Ace' clones (two), three seedlings of closely related L. formosanum (section Leucolirion), and one L. ×hybridum was used (Table 1). DNA extraction from the 'Nellie White' bulbs and all others was conducted after the completion of forcing cycle 2 in Zlesak and Anderson's (2007) morphological and greenhouse forcing study. 'Nellie White' clonal bulbs had been randomly collected from lily bulb growers in 2002 and 2003 by two independent parties to keep grower identities confidential (Zlesak and Anderson, 2007). Each 'Nellie White' genotype was coded with the year of collection (2002 or 2003), grower number, and bulb number (e.g., 5-2-1 designated a bulb collected from grower 5 in 2002 and bulb No. 1). Two 'Ace' clonal genotypes were obtained from L. Riddle (Easter Lily Research Foundation) in 2002. Three Lilium formosanum genotypes included 8265-4 (Wayside Gardens, Hodges, SC), 92-224-1 [North American Lily Society Seed Exchange (Eau Claire, WI), sourced in 2002 from Florida, code designation 4-1 (Zlesak, 2006)], and 92-225-1 [North American Lily Society Seed Exchange, sourced in 2002 from Avonsleigh, Australia, code designation 5-1 (Zlesak, 2006)]. Lilium $\times$ hybridum W-2 was an orange-flowered oriental lily (Lilium sp.) $\times$ tiger lily (L. tigrinum) hybrid from W. Gray’s 
lily breeding program (University of Minnesota, Morris) obtained in 2001.

PCR Conditions. All previously extracted DNA samples (Qiagen kit; Qiagen, Valencia, CA) at a concentration of 1 $\mathrm{ng} \cdot \mu \mathrm{L}^{-1}$ (Zlesak et al., 2007) of sufficient volume were diluted 1:100 (v/v) in deionized, distilled water before conducting ISSR analyses. Five UBC (Michael Smith Laboratories, 2008) primers from an initial screening process (Y. Sun, unpublished data) that had a high level of polymorphism and scorability were used for ISSR, PCR amplification (Table 2). Each PCR contained 0.25 units of Flexitaq ${ }^{\text {TM }}$ DNA polymerase (Promega, Madison, WI), $20 \mu \mathrm{m}$ of a single primer, $10 \mathrm{~mm}$ dNTP, $1.0 \mathrm{~mm}$ $\mathrm{MgCl}_{2}, 2 \mu \mathrm{L}$ of diluted DNA solution, and $5 \times$ Flexi buffer $^{\mathrm{TM}}$ (Promega), which was supplied with the polymerase, for a total volume of $25 \mu \mathrm{L}$ in each reaction (Yamagishi et al., 2002). Amplifications were carried out in a thermocycler (PTC-100; MJ Research, Hayward, CA) for $7 \mathrm{~min}$ of initial heating at $94{ }^{\circ} \mathrm{C}$ followed by 50 cycles of temperatures (denaturing at $94{ }^{\circ} \mathrm{C}$ for $30 \mathrm{~s}$, annealing at $43{ }^{\circ} \mathrm{C}$ for $70 \mathrm{~s}$, extension at $72{ }^{\circ} \mathrm{C}$ for $120 \mathrm{~s}$, and a 7 -min final extension at $72^{\circ} \mathrm{C}$ ). PCRs and replications of

Table 1. Lilium bulb genotype samples from easter lily bulb growers (Smith River, CA and Brookings, OR) in 2002 and 2003 and comparison species/cultivars used for intersimple sequence repeat analysis.

\begin{tabular}{lcccr}
\hline & & \multicolumn{3}{c}{ Bulbs sampled (no.) } \\
\cline { 3 - 5 } Species & Cultivar & Grower & 2002 & 2003 \\
\hline L. longiflorum & Nellie White & 2 & 14 & 14 \\
& & 3 & 13 & 14 \\
& & 4 & 14 & 14 \\
& & 5 & 14 & 14 \\
& & 7 & 14 & 14 \\
& & 9 & 14 & 14 \\
& & 12 & 14 & 14 \\
& & 13 & 14 & 14 \\
Total no. of bulbs & & 14 & 5 & 14 \\
Comparisons & & & 144 & 165 \\
L. longiflorum & Ace & & & \\
L. formosanum & $8265-4,4-1,5-1$ & - & - & 3 \\
L. $\times$ hybridum & W-2 & - & - & 1 \\
\hline
\end{tabular}

Table 2. Five University of British Columbia [UBC (Michael Smith Laboratories, 2008)] intersimple sequence repeat primer configurations of $5^{\prime}-3^{\prime}$ sequence, length in basepairs, melting temperature (Tm), total loci, and total polymorphic loci or amplicons used with Lilium longiflorum 'Nellie White', 'Ace' clones, species, and hybrids in this experiment.

\begin{tabular}{lccccc}
\hline $\begin{array}{l}\text { UBC } \\
\text { primer }\end{array}$ & Sequence & $\begin{array}{c}\text { Length } \\
(\mathrm{bp})\end{array}$ & Tm $\left({ }^{\circ} \mathrm{C}\right)$ & $\begin{array}{c}\text { Total loci } \\
(\text { no. })\end{array}$ & $\begin{array}{c}\text { Total polymorphic } \\
\text { loci [no. }(\%)]\end{array}$ \\
\hline 808 & $5^{\prime}-(\mathrm{AG})_{8} \mathrm{C}-3^{\prime}$ & 17 & 48.8 & 14 & $12(85)$ \\
810 & $5^{\prime}-(\mathrm{GA})_{8} \mathrm{~T}-3^{\prime}$ & 17 & 45.4 & 17 & $11(64)$ \\
811 & $5^{\prime}-(\mathrm{GA})_{8} \mathrm{C}-3^{\prime}$ & 17 & 46.8 & 16 & $11(68)$ \\
814 & $5^{\prime}-(\mathrm{CT})_{8} \mathrm{~A}-3^{\prime}$ & 17 & 44.7 & 15 & $11(73)$ \\
818 & $5^{\prime}-(\mathrm{CA})_{8} \mathrm{G}-3^{\prime}$ & 17 & 51.0 & 15 & $11(73)$ \\
Total & & & & 77 & $56(72.7)$ \\
\hline
\end{tabular}

gels for each primer are rarely exactly identical due to minor differences in primer, polymerase, and temperature ramping. Variation at the commencement of a thermal cycle may also be amplified exponentially. All of these can create variation between replications. Thus, to verify the consistency and repeatability of the results (scorable bands) for each DNA sample, PCRs and gel electrophoresis of the PCR amplifications were replicated. Initial PCRs were replicated two to four times for five primers [UBC $808,810,811,813$, and 814 ; note that 813 was later determined to not be polymorphic (Table 2)] for 52 lily genotypes representing $L$. formosanum ( $n=3$ genotypes), L. Xhybridum $(\mathrm{n}=1)$, L. longiflorum 'Ace' $(\mathrm{n}=2)$, and 'Nellie White' bulbs samples $(\mathrm{n}=46)$ from growers $2,3,5,7$, and 11 . Reproducible banding patterns of the ISSR amplification products were confirmed with the two to four PCRs of the 52 test genotypes (Y. Sun, unpublished data) before subsequent PCR and gel electrophoresis (three replications) for all genotypes in this experiment (Monte-Corvo et al., 2001).

GEL ELECTROPHORESIS. A 1.5\% agarose (mixed with $100 \mathrm{~mL}$ of electrophoresis, $1 \times$ Tris Acetate) buffer was made and heated in a microwave at high power for $\approx 2$ min until melted. Ethidium bromide was added to the gel (final concentration of $0.5 \mu \mathrm{g} \cdot \mathrm{mL}^{-1}$ ) at this point to facilitate DNA visualization. Electrophoresis chambers were filled with $1 \times$ Tris Acetate EDTA plus $5 \mu \mathrm{g} \cdot \mathrm{mL}^{-1}$ ethidium bromide (Sambrook et al., 1989). Sample DNA volumes (12 mL) were then loaded and a current of $75 \mathrm{~V}$ was applied for 2 to $2.5 \mathrm{~h}$. Gels were visualized under ultraviolet light and were recorded with a Fluro Chem 500 camera (Alpha Innotech, Santa Clara, CA).

Data ANALYSES. Unequivocally scorable and consistently reproducible amplified DNA fragments across all three replications were transformed into binary character matrices $(1=$ presence, $0=$ absence). Cross Checker (Buntjer, 1999) was used to score and analyze binary interpretation of DNA fingerprints. To minimize variation, gels were equilibrated to comparable background coloration and alignment using the Cross Checker Gel Manager macro. Intra- and intergrower (population) variations were measured using Hedrick's index [I (Hancock and Bringhurst, 1979)]. To obtain interpopulation variance estimates, Russell and Rao (1940) coefficients of similarity were calculated. Clustering and dendrograms for individual growers or pooling all growers within each year were created by the unweighted pair group method (UPGMA) using the SAHNclustering and TREE programs from NTSys (version 2.02; Exeter Software, Setauket, NY). ISSR primer data for all bulb growers were pooled by years (2002 and 2003) to evaluate the 'Nellie White' genetic variation among growers. It was not feasible to also pool all growers and years together into one analysis due to software limitations; i.e., Excel ${ }^{\circledR}$ (Microsoft, Redmond, WA) did not have sufficient line numbers to handle the number of data sets. Genetic diversity among and within populations of 'Nellie White' clones and comparisons (binary diploid data) were estimated with an analysis of molecular variance (AMOVA) in GenAlEx (Peakall and Smouse, 2006). The $H_{o}$ tested = there is no genetic difference among the populations $(\Phi p t=0)$; i.e., they are 
clones that have the opportunity to cross-pollinate due to close proximity of all easter lily bulb growers and, thus, may all be "part of a single large random mating genetic population" (Peakall and Smouse, 2006).

\section{Results}

A total of 77 well-defined (clear and unequivocal bands) and scorable markers across replications were obtained from five of the selected ISSR primers, 56 (72.7\%) of which were polymorphic (Table 2). Replications did not differ significantly in their banding patterns. The size of the scorable amplified fragments ranged from 1018 to $8144 \mathrm{bp}$. Total numbers of scorable loci/primer ranged from 14 (Primer 808) to 17 (Primer 810) for 'Nellie White' clones and comparison genotypes (Table 2), whereas the number of scorable, polymorphic loci/primer ranged from 11 (all primers, except Primer 808) to 12 (Primer 808 only) (Table 2). This set of 56 polymorphic marker loci enhanced the stringency for discernment of 'Nellie White' clones.

As would be expected with varying numbers of polymorphic loci for each of the five primers, differing numbers of scorable bands for 'Nellie White' populations were found. For example, gel profiles of 'Nellie White' ramets obtained from grower

7 for 2002 and 2003, using Primers 810 (Fig. 1A) and 811 (Fig. 1B), show differing numbers of scorable bands. Bulb 7-2-2 has three scorable bands with Primer 810 (Fig. 1A, lane 3 ), whereas only one band is scorable with Primer 811 (Fig. 1B, lane 3). As would be expected, because the 2002 and 2003 samples were randomly collected from each grower, rarely did any bulb genotype from 2002 have a comparable amplified fragment banding pattern with bulbs harvested in 2003. Because bulb numbers were assigned at random within each grower lot and year, one would not expect any relationship between genotypes with the same bulb number if the 'Nellie White' clones are genetically divergent, other than what might occur by chance alone. Comparable, scorable loci for ramet 7-2-2 with only one scorable locus using Primer 811 (2002; Fig. $1 \mathrm{~B}$, lane 3 ) is expressed in the 2003 genotypes 7-3-1, 7-3-5, 7-3-8, $7-3-10,7-3-11$, and 7-3-14, although each of these also have additional scorable loci for this primer and, thus, are not identical to 7-2-2 as would be expected in a clone (Fig. 1B). Similar analogies commonly surfaced with all clonal ramets from the same bulb grower between years and within primers. Thus, 'Nellie White' clonal ramet populations among growerseither between or within sampling years - were not homogeneous for the ISSR polymorphic loci and could not be pooled (Table 3).
Constructed dendrograms for each bulb grower for 2002 and 2003 differed widely, with no two growers being identical. For instance, for bulbs obtained from grower 11 in year 2002, the dendrogram delineates ramets into two principal groups separating at Nei's (1972) genetic distance of GD $=0.63$ (Fig. 2), with only two subsequent monophyletic singletons (a set with exactly one genotype or clonal ramet) found (11-2-13, 11-2-4). Each principal group further separated into 2, 3, or 4 additional overlapping, contiguous clades (contigs) (Fig. 2). Pairs of clones (bulbs) separated at low to higher GDs, e.g., GD $\approx$ 0.69 for $11-2-6$ and $11-2-14 ; \mathrm{GD} \approx 0.73$ for pairs $11-2-7 / 11-2-3$ and $11-2-11$ and $11-2-5 ; \mathrm{GD} \approx 0.75$ for pairs $11-2-8 / 11-2-9$ and 11-2-10/11-2-1; and GD $\approx 0.8$ for $11-2-2 / 11-2-12$ (Fig. 2). Thus, in this example, the most closely related clones from grower 11 in 2002 are 11-2-2 and 11-2-12 (GD =0.8).

In contrast with the findings for grower 11 in 2002 (Fig. 2), the principal clades in grower 3 for 2003 bulbs separated at a higher GD of 0.67 (Fig. 3). This separation constituted one singleton, genotype 3-3-13, with all remaining bulbs in a separate clade, which subsequently split into several subclades. The most closely related 'Nellie White' clonal genotypes, 3-3-4 and 3-3-5, had a GD $=0.89$ (Fig. 3). Thus, these two bulbs are even more related than 11-2-2 and 11-2-12 (GD=0.8, Fig. 2). A summary of GD values (principal clade separations, most-related 
Table 3. Analyses of molecular variance (AMOVAs) for Lilium longiflorum 'Nellie White' sourced from bulb growers in 2002 (11 populations), 2003 (12 populations), and one comparison population of cultivars (Table 2) on the basis of intersimple sequence repeats (ISSRs).

\begin{tabular}{|c|c|c|c|c|c|c|c|c|}
\hline \multirow[b]{2}{*}{$\begin{array}{l}\text { Source of } \\
\text { variation }\end{array}$} & \multicolumn{4}{|c|}{2002} & \multicolumn{4}{|c|}{2003} \\
\hline & $\begin{array}{l}\text { Sum of } \\
\text { estimate }\end{array}$ & Variation & df & $\begin{array}{c}\text { Squares of } \\
\text { variation }(\% \text { total })\end{array}$ & $\begin{array}{l}\text { Sum of } \\
\text { estimate }\end{array}$ & Variation & $\mathrm{df}$ & $\begin{array}{c}\text { Squares of } \\
\text { variation ( } \% \text { total) }\end{array}$ \\
\hline Among populations & 12 & 314.3 & $1.69^{* * \mathrm{z}}$ & 18.0 & 13 & 402.5 & $2.01 * * y$ & 18.0 \\
\hline Total & 150 & 1390.1 & 9.66 & 100.0 & 171 & 1717.2 & 11.02 & 100.0 \\
\hline
\end{tabular}

${ }^{\mathrm{z}}$ Genetic distance between populations $(\Phi p t)=0.175(P \leq 0.01)$.

${ }^{\mathrm{y}} \Phi p t=0.183(P \leq 0.01)$.

bulbs) from ISSR dendrograms for individual growers for each year (2002 and 2003) are summarized in Table 4. Principal clades ranged from $\mathrm{GD}=0.60$ (growers 2, 4, and 12) to $\mathrm{GD}=0.82$ (grower 6 ) for 2002 bulbs, whereas the 2003 bulbs resulted in GD $=0.51$ (grower 4) to $\mathrm{GD}=0.78$ (grower 14) (Table 4). Across years 2002 and 2003, grower 4 consistently had the lowest principal clade. However, grower 5 had identical principal clade separations of GD $=0.71$ in both years (Table 4 ). The remaining bulb growers had lower or higher principal clade separation GDs between harvest years.

GD values for the most-related bulbs in 2002 ranged from GD = 0.80 (growers 11 and 12) to GD = 0.95 (grower 6) (Table 4). A wider range of values for the most-related 2003 bulbs: $\mathrm{GD}=0.70$ (grower 4$)$ to GD $=0.91$ (grower 6) (Table 4). Again, grower 5 had an identical most-related bulb GD value of 0.89 for 2002 and 2003. While the GD values cannot be statistically analyzed within growers and among years, the trends among years for principal group separations and most-related bulb GDs (Table 4) are intriguing. Six growers had lower GDs between 2002 and 2003 for both categories (growers 1, 2, 4, 6, 7, and 11 ); one grower had higher GDs between 2002 and 2003 for both categories (grower 12). Two growers had lower principal clade separations and higher mean related bulb GDs (growers 3 and 13); one grower had higher principal group separations and lower mean related bulb GDs (grower 14). One grower had equal values between years (grower 5).

When years were coanalyzed for each 'Nellie White' bulb grower population, the principal clade separations occurred for years or the years were scattered between both clades. In the case of grower 7, all 2003 genotypes except one (7-3-10) were in one principal clade while the 2002 bulbs plus 7-3-10 were in

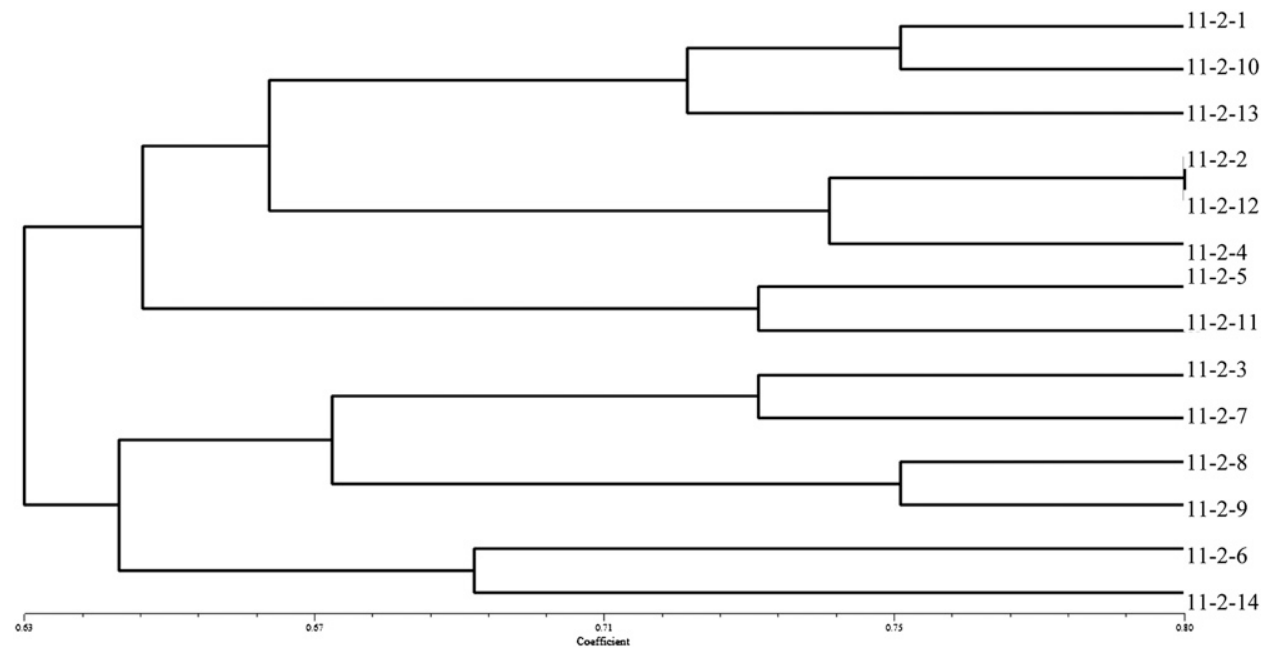

Fig. 2. Dendrograms of relatedness for Lilium longiflorum 'Nellie White' clones (grower 11, year 2002) derived from polymorphic, scorable bands for all five intersimple sequence repeat primers used $(808,810,811,814$, and 818 ) and based on using Nei's (1972) coefficients.

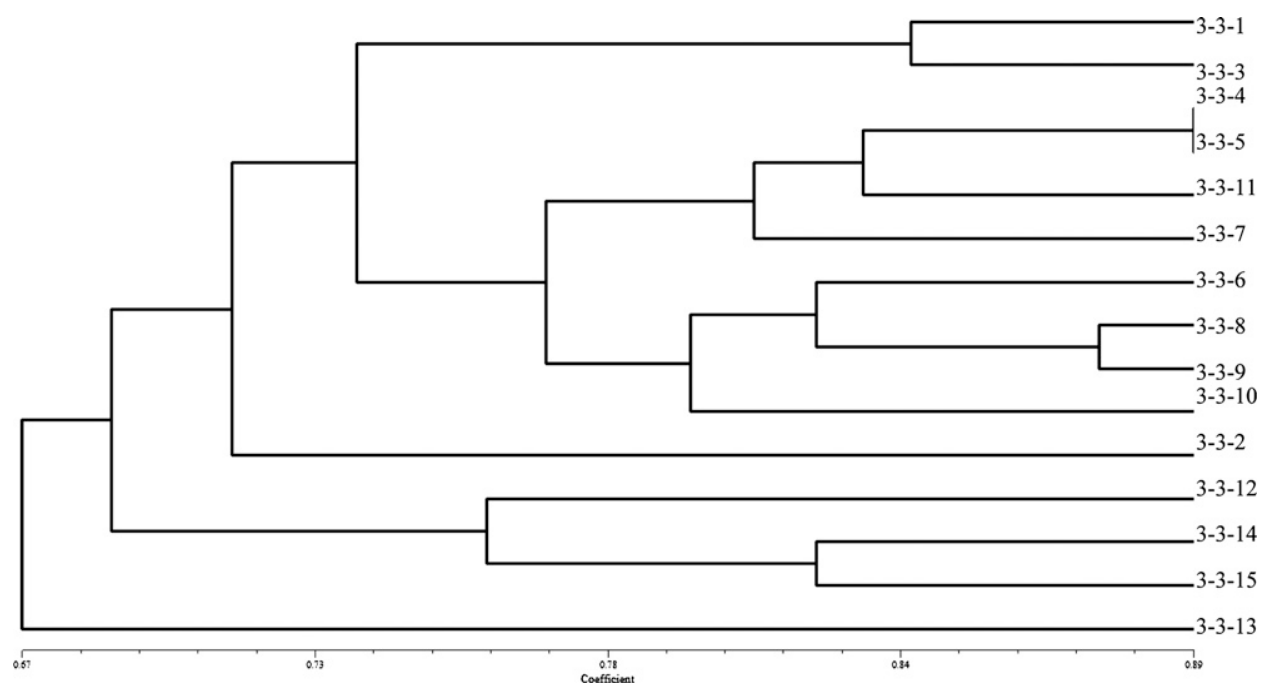

Fig. 3. Dendrograms of relatedness for Lilium longiflorum 'Nellie White' clones (grower 3, year 2003) derived from polymorphic, scorable bands for all five intersimple sequence repeat primers used $(808,810,811,814$, and 818 ) and based on using Nei's (1972) coefficients. 
one singleton (5-3-7) and all other 2002 and 2003 bulbs (Fig. 5). These principal clades then subsequently split into two subclades at $\mathrm{GD}=0.67$ with a) 10 genotypes (2003) and three genotypes (2002), b) 11 genotypes (2002) and three genotypes (2003). Such inconsistencies between years within growers were common for all bulb growers (data not shown). Thus, non-uniform clones exist with all 'Nellie White' bulb growers for each year (2002 and 2003), and the level of genetic variation is also inconsistent between years.

Table 4. Genetic distance (GD) coefficients for intersimple sequence repeats using five University of British Columbia (UBC) primers [808, 810, 811, 814, and 818 (Michael Smith Laboratories, 2008)] for the 2002 and 2003 bulb lots from easter lily bulb growers of Lilium longiflorum 'Nellie White'. GDs of the principal group separations and the most-related bulbs within each bulb lot are derived from polymorphic, scorable bands for all five primers, based on Nei's (1972) coefficients.

\begin{tabular}{cccccc}
\hline \multirow{2}{*}{$\begin{array}{l}\text { Grower } \\
\text { no. }\end{array}$} & $\begin{array}{c}\text { Principal } \\
\text { clad }\end{array}$ & $\begin{array}{c}\text { Most-related } \\
\text { separation bulbs }\end{array}$ & & $\begin{array}{c}\text { Principal } \\
\text { clade }\end{array}$ & $\begin{array}{c}\text { Most-related } \\
\text { separation bulbs }\end{array}$ \\
\hline 1 & 0.74 & 0.93 & 0.58 & 0.84 \\
2 & 0.60 & 0.85 & & 0.54 & 0.83 \\
3 & 0.73 & 0.85 & & 0.67 & 0.89 \\
4 & 0.60 & 0.85 & & 0.51 & 0.70 \\
5 & 0.71 & 0.89 & 0.71 & 0.89 \\
6 & 0.82 & 0.95 & 0.74 & 0.91 \\
7 & 0.63 & 0.85 & 0.58 & 0.80 \\
9 & - & 0.80 & 0.59 & 0.89 \\
11 & 0.63 & 0.80 & 0.61 & 0.83 \\
12 & 0.60 & 0.83 & 0.62 & 0.84 \\
13 & 0.61 & 0.89 & 0.53 & 0.85 \\
14 & 0.76 & & 0.78 & \\
\hline
\end{tabular}

When bulbs from all the growers in year 2002 were pooled together, the principal clades separated at GD $=0.54$ with the three L. formosanum genotypes (4-1, 5-1, and 8265-4) in one monophyletic clade and all other genotypes (all 'Nellie White', 'Ace' clones, and L. Xhybridum W-2) in the second clade (data not shown). Within L. formosanum, 8265-4 separated into a subclade at $\mathrm{GD}=0.75$ with genotypes $4-1$ and $5-1$ differentiated at $\mathrm{GD} \approx 0.76$ (data not shown). The other principal clade separated at GD $=0.573$ into one subclade with all of grower 7 'Nellie White' genotypes and the other clade containing all of the remaining 'Nellie White', 'Ace', and W-2 genotypes (data not shown). Clearly, in 2002, there is significant genetic variation between grower 7 and all other 'Nellie White' bulb growers. The next subclade within L. longiflorum split at $\mathrm{GD}=0.594$ with all of grower 11 'Nellie White' genotypes in one subclade, completely separate from the remaining clones (data not shown). Bulbs from grower 11 in 2002 had enough distinctive genetic variation to distinguish them from growers 1-6, 9, and 12-14. Following the first subclade, there were a total of 15 subgroupings splitting the genetic variation between 'Nellie White' bulb growers, 'Ace', and W-2. No clear patterns emerged with 'Nellie White' bulbs from each

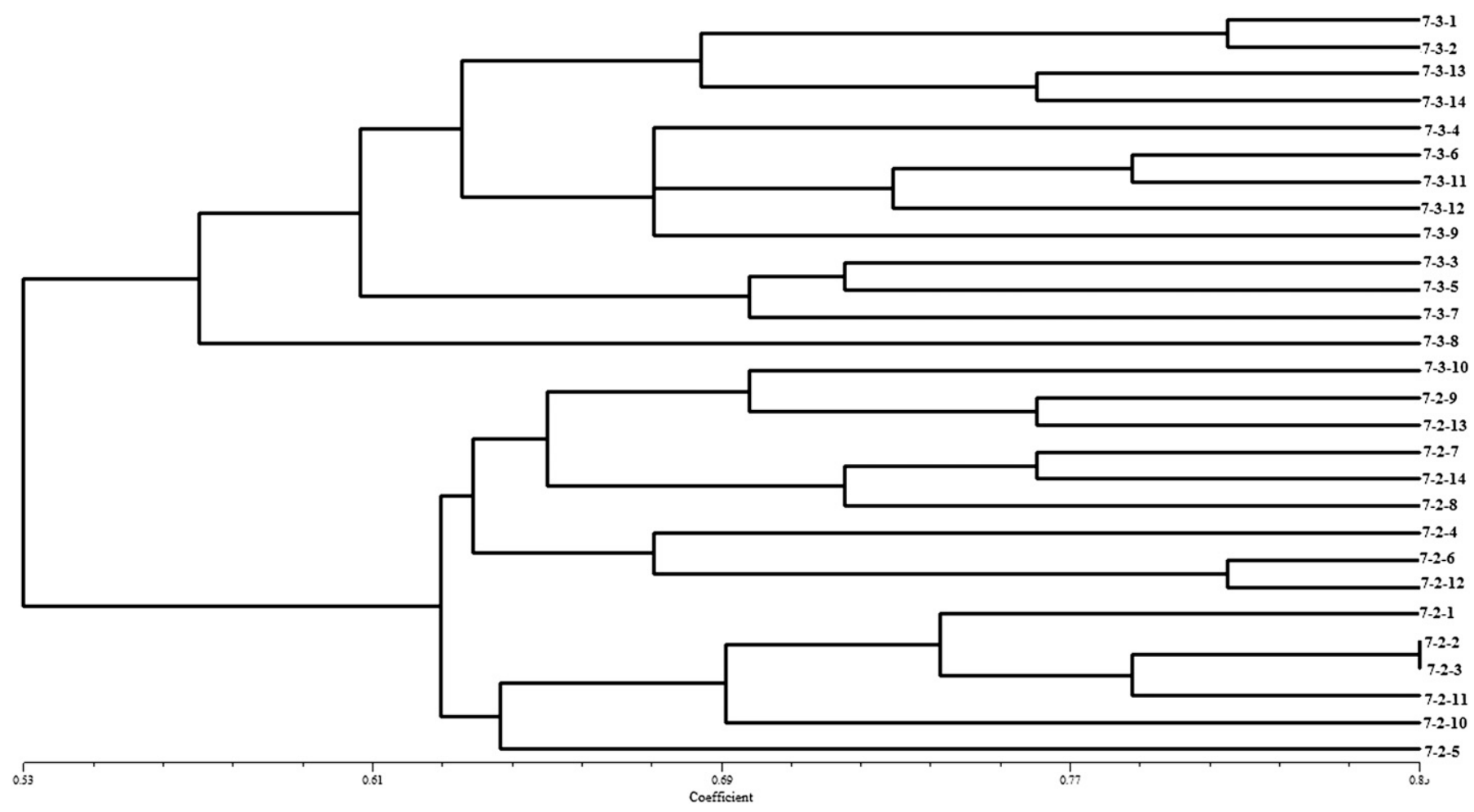

Fig. 4. Dendrograms of relatedness for Lilium longiflorum 'Nellie White' clones (grower 7 pooled for years 2002 and 2003) derived from polymorphic, scorable bands for all five intersimple sequence repeat primers used $(808,810,811,814$, and 818) and based on using Nei's (1972) coefficients. 


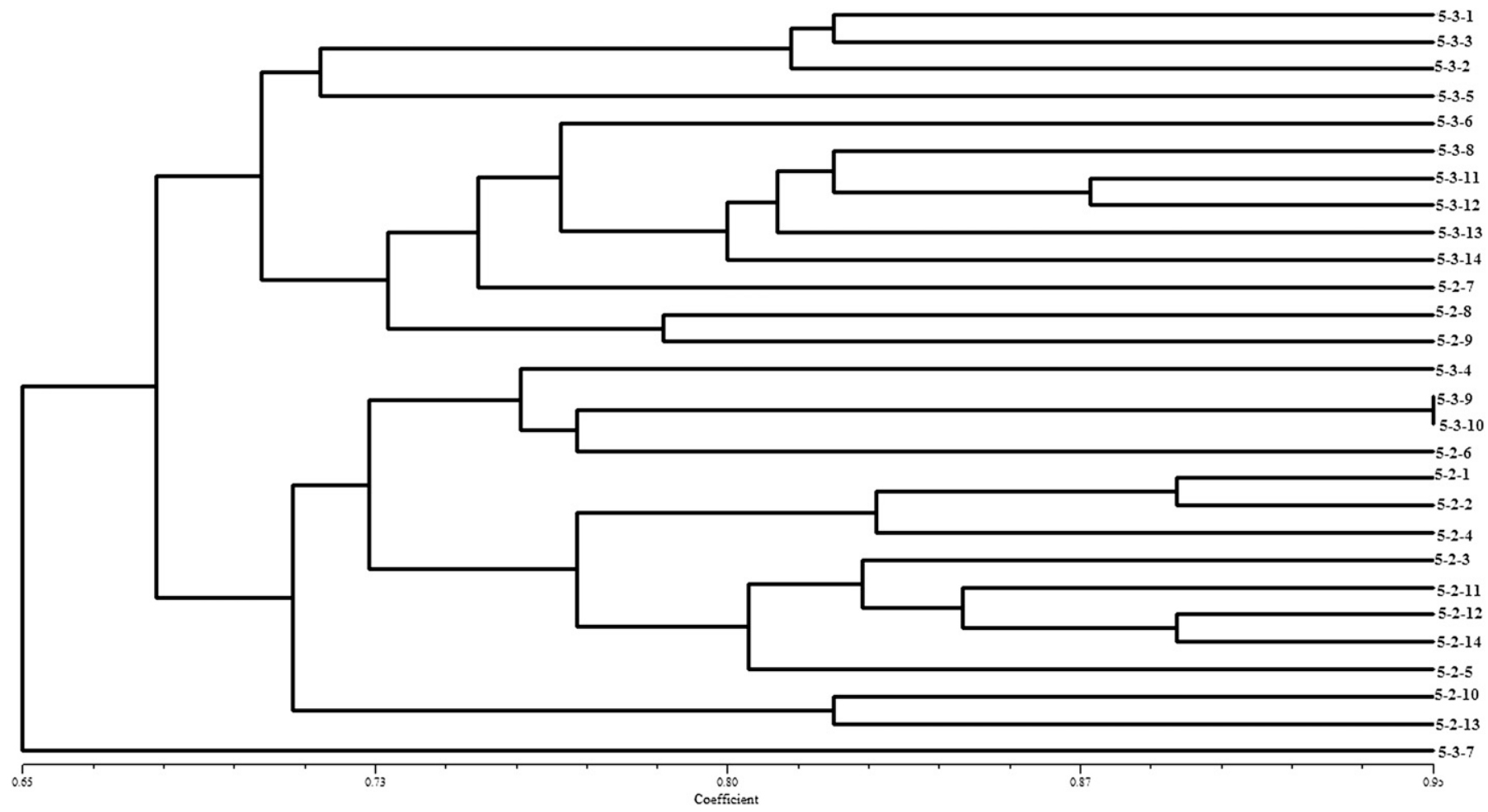

Fig. 5. Dendrograms of relatedness for Lilium longiflorum 'Nellie White' clones (grower 5 pooled for years 2002 and 2003) derived from polymorphic, scorable bands for all five intersimple sequence repeat primers used (808, 810,811,814, and 818) and based on using Nei's (1972) coefficients.

grower dispersed narrowly or widely through multiple subclades (data not shown).

In contrast with the 2002 dendrogram, when the 2003 bulb lots were pooled for all growers (data not shown), the principal clades consisted of a) six 'Nellie White' genotypes (7-3-08, 2-3-06, 4-3-08, 13-3-02, 13-3-04, 11-3-04, and 13-3-05) and b) all other L. longiflorum, L. formosanum, and L. Xhybridum accessions. The latter principal clade subsequently split into two subclades at GD $=0.524$ containing a) three genotypes: $L$. formosanum 5-1, 4-1, and L. longiflorum 'Nellie White' 14-304 ; b) all other remaining genotypes in the experiment (data not shown). Subclade $b$ then split at GD $=0.557$ into two subgroups of ba) seven bulbs from grower 1 (1-3-03, 1-3-02, 1-3-05, 1-3-06, 1-3-07, 1-3-08, and 1-3-04) and one bulb from grower 5 (5-3-07); bb) all remaining genotypes (data not shown). The latter subgroup bb split again into 18 additional subgroupings with scattered representation of bulbs from each grower spread narrowly or broadly across subgroupings (data not shown). Genetic variation displayed in the 2003 bulb lots differed widely from the variation in 2002 with an even more diverse set of 'Nellie White' clones, some of which exceeded the genetic variation found between L. formosanum, L. Xhybridum, and L. longiflorum.

AMOVAs showed higher levels of genetic diversity within ( $82 \%$ of variation), rather than among $(18 \%)$, 'Nellie White' and comparison populations (Table 3 ). Identical percentages of variation results were found within and among populations across years (2002 and 2003), although the sums of squares and df differed (Table 3). For 'Nellie White' bulbs from 2002, $\Phi p t=$ 0.175 and the null hypothesis were rejected $(P<0.01)$. Thus, all 'Nellie White' clones are not part of a single, random-mating population (Peakall and Smouse, 2006). Likewise, in 2003, $\Phi p t=0.183(P<0.01)$.

\section{Discussion}

ISSRs distinguished among- and within-bulb grower populations of 'Nellie White' clones (ramets) and confirmed the lack of a single clone for this cultivar. The five selected UBC primers, with $\mathrm{A}, \mathrm{T}, \mathrm{C}$, or $\mathrm{G}$ anchors at the $3^{\prime}$ end, provided 56 polymorphic, unequivocally scorable markers of fragment sizes 1018 to 8144 bp (Table 2). A, T, C, and G anchors, C-T repeats, or C-A and $\mathrm{G}-\mathrm{A}$ repeats at the $3^{\prime}$ end have been useful for ISSR markers in Glycine (Wang et al., 1998), asiatic Lilium (Yamagishi et al., 2002), and interspecific Lilium hybrids (Anderson et al., 2009; Wang et al., 2009). This set of polymorphic marker loci enhanced the stringency for discernment of 'Nellie White' clonal ramets. The number of primers:scorable markers used for L. longiflorum 'Nellie White' [5:56 (Table 2)] is similar to previous reports involving ISSRs for L. longiflorum 'Gelria' [4:38 (Wang et al., 2009)] and within species or closely related clones $\{2: 56$ for Linaria vulgaris populations (Ward et al., 2008), 4:14 for the mother ortet (the original hybrid plant from which clones or ramets are derived) and clonal ramets (vegetative propagules derived from the original ortet or subsequent ramets) of Camellia (Devarumath et al., 2002), but slightly smaller than those for more divergent species analyses [12:103 for Prunus (Liu et al., 2007)]\}.

'Nellie White' clonal ramets among growers - between or within sampling years - are not homogeneous for the ISSR polymorphic loci and are not part of a single, random-mating population (Table 3; Peakall and Smouse, 2006). Rather, there are several random-mating grower populations. Within growers, as few as two ramets shared similarity with each other, ranging from Nei's GD = 0.7 [grower 4, 2003 (Table 4)] to $\mathrm{GD}=0.95$ [grower 6, 2002 (Table 4$)]$. Within years, the most 
closely related clones among growers for 2002 were four at $\mathrm{GD}=0.96$ : 4-2-13 and 13-2-3; 2-2-2 and 4-2-2 (data not shown) and in 200310 clones at GD =0.98: 7-3-3 and 14-3-3, 5, 6; 14-3-1 and 3-3-14, 15; 14-3-9, 10 and 3-3-10 (data not shown) representing 2.78\% [4/144 (2002)] and 6.1\% [10/165 (2003)] nuclear genome similarity. Conversely, 97.2\% (2002) and 93.9\% (2003) of 'Nellie White' were clonally variable. These levels of nuclear genome variation are significantly higher than those reported for Coffea [4.38\% (Rani et al., 2001)] and Camellia [7.43\% (Devarumath et al., 2002)]. The nearly identical 'Nellie White' clones involved a minority of growers - three in each year [growers 2, 4, and 13 (27.3\% in 2002); growers 3, 7, and 14 (25\% in 2003)] -rather than a majority, as would have been expected with a clonal cultivar with absolute genetic fidelity. These low levels of ISSR genetic similarity within 'Nellie White' resemble what has been previously reported for clonal Camellia (Devarumath et al., 2002), Achillea (Wallner et al., 1996), Populus (Rani et al., 1995, 2001), and Coffea (Rani et al., 2000).

Because the identical 2002 and 2003 harvested 'Nellie White' bulbs used in this ISSR study were also evaluated in two forcing cycles (FC) to record phenotypic (morphological) responses (Zlesak and Anderson, 2007), comparative analyses of the common genotypes is possible herein (even though ISSR markers are usually neutral in expression). The FCs consisted of FC1 (freshly harvested bulbs forced to flower the following spring) and FC2 (reforcing the FC1 bulbs an additional year) for the 2002 and 2003 harvested bulb lots from all growers. All FC1 bulbs, while grown in grower fields of close proximity in Brookings, OR, and Smith River, CA, had differing environmental factors that could compound $\mathrm{G} \times \mathrm{E}$ interactions for phenotypic analyses only (Zlesak and Anderson, 2007). In contrast, the FC2 bulbs had the uniform greenhouse FC1 and subsequent cooling environments that minimized the $\mathrm{G} \times \mathrm{E}$ variation inherent in FC1. Zlesak and Anderson (2007) evaluated critical commercial greenhouse forcing [e.g., quick emergence and flowering, particularly for early Easters, high flower bud number, and shorter plant height (Lange and Heins, 1990; Wilkins and Roh, 1976)], and other traits that make an ideal flowering potted plant. In general for all traits, grower 5 ranked among the top five grower lots $(1,3,4,5$, and 6$)$ for all key traits in 2003 FC1 and all traits except plant height in 2002 FC1, and number of days to stem emergence in 2003 FC2 (Zlesak and Anderson, 2007). Grower 3 was also ranked in the top five grower lots for these traits, except for days to stem emergence in 2003 FC2 and plant height in 2002 FC1, 2003 FC2. In 2002, growers 3 and 5 'Nellie White' genotypes were clustered across the ISSR subgroup separating at $\mathrm{GD}=0.594$ that included all top five growers [1, and 3-6 (Zlesak and Anderson, 2007)], plus a couple of outlier genotypes from growers 12 and 13. They were distributed across similarly large ISSR subclades in 2003 (separating at GD $=0.557$ ) that included most of the top five growers (plus a few outliers from grower 4), but others as well.

The number of days to stem emergence in 2002 FC1 followed the trend for the pooled morphological data, with growers 3 and 5 emerging significantly earlier than growers 2, 7, 11 through 14, and all of the top five growers (1, and 3-6) overlapping (Zlesak and Anderson, 2007). Likewise, visible bud and anthesis dates were significantly earlier for the top five growers in 2002 FC1 (Zlesak and Anderson, 2007). These top five growers were in the same ISSR subclade (data not shown), as noted earlier. In $2003 \mathrm{FC} 1$, only grower 11 emerged significantly later than growers 3,5 , and 13 , while the number of days to visible bud were earliest for growers 3 and 5 (Zlesak and Anderson, 2007), but the ISSR genetic distances showed a widespread distribution across clades for grower 11 bulbs (Fig. 6B). In contrast, for 2003 FC2, only grower 4 was significantly earlier to emerge than grower 1 while the rest overlapped (Zlesak and Anderson, 2007). Genetic distances of growers 1 and 4 bulbs were intermixed across the dendrogram (data not shown).

Flower number differed slightly from trends noted with days to emergence, visible bud, and anthesis in 2002 FC1 with growers 1, 3, 5, 6, and 7, and grower 13 in $2003 \mathrm{FC} 1$ (rather than growers 1, and 3-6) having the significantly highest bud counts (Zlesak and Anderson, 2007). Flower number does not fit the ISSR GD configurations quite as tightly as emergence and flowering traits. Plant height and leaf measurements (length, width, and length:width ratios) also followed a similar trend. Thus, ISSR genetic distances only matched some (days to emergence, visible bud, and anthesis), but not all, morphological traits for the top five growers in 2002 and 2003. These results are not unusual, as "functional" phenotypic variation is only inferential but "cannot be measured directly" (Ward et al., 2008).

Higher levels of genetic diversity were consistently found within $(82 \%)$ than among 'Nellie White' grower populations for each of the years sampled (Table 3). Thus, only an $18 \%$ difference in genetic variation exists between growers-an astounding fact since each grower serves as their own propagator of 'Nellie White' (Zlesak and Anderson, 2003, 2007). However, the high within-grower variation is significant and reflective of each grower deliberately selecting from among differing clonal ramet populations for propagules (Zlesak and Anderson, 2003, 2007), causing genetic drift. Low amonggrower variation levels may be influenced by growers purchasing bulbs from their competitors to generate additional ramets. Despite the lack of a central propagator to ensure clonal integrity, bulb growers may select a suite of superior ramets with a similar range in phenotypes $(82 \%)$ to ensure that greenhouse forcers can produce a marketable crop each year. Even though grower field conditions can vary significantly, the close proximity of bulb growers may create enough environmental similarity among growers that favor a similar range of ramet selections. In years when Easter is early, the 18\% among grower variation could be enough to offset reaching the target flowering date if a grower were, by chance, to purchase bulbs that performed significantly different from the norm $(82 \%)$. Commercial greenhouse bulb forcers of easter lily-both currently for 'Nellie White' and previously with older clones ['Ace', 'Croft', 'Chetco', 'Harbor' (Roberts et al., 1968)]- have been advised to purchase from multiple growers each year to avoid chance variation in bulb lots, which could mean missing the Easter target flowering date, particularly when Easter is early (Zlesak and Anderson, 2003, 2007). Phenotypic variation during the four forcing phases (i.e., shoot elongation, flower initiation, flower development, and senescence) can be environmentally manipulated by the grower to ensure that the crop flowers for Easter (Fanelli and De Hertogh, 2002; Roberts et al., 1983). Erwin and Engelen-Eigles (1998) postulated that phenotypic variation in potted easter lily (days to emergence, leaf and flower number, height, and internode length) was also attributable to bulb maturity, dormancy level differences (bulb lots and years), and environmental factors during shipping and greenhouse forcing. Zlesak and Anderson (2007) forced the same bulbs 
tested in our present ISSR analysis over two forcing cycles and found, among bulb lots, the existence of significant morphological variation for all traits except visible bud and anthesis dates. The low (18\%) level of genetic variation between grower bulb lots may be a significant underlying genetic/epigenetic factor affecting the significant phenotypic (morphological) differences operating in tandem with other inherent (lily symptomless virus titer) or external (initial bulb size, the previous forcing cycle environment) factors (Roberts et al., 1968; Zlesak and Anderson, 2007).

It is unknown whether there were one or more 'Nellie White' bulbs (ortet/s) used to propagate this clone. Regardless of whether there were one or two ortets, both would have been submitted to multiple asexual generations without meiosis, which allows for the continued accumulation of mutations due to the operation of Muller's ratchet (Anderson and Ascher, 1994; Muller, 1964). Clearly, there were several mutational populations, rather than one or two. Whether this is due to the origination of 'Nellie White' from one ortet or several, numerous populations of mutants have arisen during the $>60$ years of asexual propagation. The most closely related clones of 'Nellie White' in 2002 and 2003 had a wide range of GDs, i.e., 0.7 (grower 4, 2003) to 0.95 [grower 6, 2002 (Table 4)]. It would have been expected that all 'Nellie White' clones, particularly those from the same grower (within populations) would be closely related $(\mathrm{GD} \approx 1.0)$ if they were derived from the same ortet and remained free of mutation(s). However, because $82 \%$ of the variation consistently occurred within populations (growers) in 2002 and 2003, it is more likely that mutations, regardless of the number of original 'Nellie White' ortets, are accumulating within growers bulb stock due to the operation of Muller's ratchet (Anderson and Ascher, 1994; Muller, 1964). Due to a lack of the meiotic sieve of sexual cycles, every clonal (asexual) generation can accumulate deleterious recessive alleles (i.e., every asexual generation is a click of the ratchet). Eventually, such mutations can result in lowered fertility levels (male/female; Anderson and Ascher, 1994) or phenotypic differences that have caused growers to purchase from multiple bulb growers (Zlesak and Anderson, 2003, 2007). This scenario will continue in 'Nellie White' until such mutations become severe enough to necessitate clonal replacement. The large genome size of lily may predispose 'Nellie White' clones to survive numerous clicks of the ratchet before becoming phenotypically visible. This, coupled with the levels of viruses present (e.g., lily symptomless virus), which are removed only when the viral titer becomes high enough to stunt the plants, may have been the causal factor in the removal of 'Ace' and 'Croft' from the market after they began developing high rates of leaf scorch (Zlesak and Anderson, 2003).

Comparison cultivars and species also varied in their genetic relatedness to each year's 'Nellie White' ramet populations. For instance, in 2002, all L. formosanum genotypes were genetically distinct from 'Nellie White' clones as well as 'Ace' and L. $\times$ hybridum, separating into a separate clade at GD $=0.54$ (data not shown). In contrast, L. formosanum in 2003 were not in a distinct clade, but separated out at a higher GD (data not shown), with two genotypes (5-4 and 4-1) in the same subgroup as 'Nellie White' 14-3-4. 'Ace' clones and L. Xhybridum were in the middle of the entire 'Nellie White' clonal distribution, changing only slightly between years (data not shown). It would have been expected that L. Xhybridum would have been the most genetically distant from L. longiflorum 'Nellie White' and/or 'Ace' across years, with L. formosanum more closely related, since $L$. formosanum and $L$. longiflorum are in the Section Leucolirion, whereas L. Xhybridum is from different sections of the genus (Booy et al., 1998; Yamagishi et al., 2002). Reasons for the genetic distinction of $L$. formosanum from L. longiflorum in 2002, but the closer similarity in 2003, are unclear. This could have been due to chance mutations accumulating with the operation of Muller's ratchet (Anderson and Ascher, 1994; Muller, 1964) and/or inadvertent crosshybridization between L. longiflorum and L. formosanum because the latter species has been grown at the Easter Lily Research Station, which is adjacent to several bulb growers' fields. Grower 14's location is unknown to the authors, but one of its 'Nellie White' bulbs, 14-3-4, was in the same 2003 subclade as two L. formosanum (data not shown). Also equally likely is the chance that 14-3-4 and L. formosanum share common genetic makeup for the tested nuclear DNA sequences because ISSRs are arbitrary multiloci markers (Levinson and Gutman, 1987).

Analyzing populations of clonally propagated plants is difficult because a single genetic individual (ramet) may comprise many morphological units that appear distinct (Parks and Werth, 1993). Clearly, 'Nellie White' clones are genetically distinct from each other primarily within growers over years and, to a lesser extent, among growers. The current study is the first to use ISSR markers to characterize genetic variation in L. longiflorum 'Nellie White' clones. Without molecular genetic investigations, such clonal drift would not have been detected. For instance, phenotypic variation showed clonal ramets from growers 3 and 5 as the best-performing sources (Zlesak and Anderson, 2007), but the molecular variation (ISSR data herein) show these populations to be intermediate in GD (Table 4). Nonetheless, the clonal variation in 'Nellie White' is significant and a cause for greenhouse growers to continue exercising caution to reach critical forcing landmarks for early Easters. There is also a need for increased clonal integrity within this important floricultural crop to ensure reduced genetic variation. Natural mutations (Veilleux and Johnson, 1998), Muller's ratchet, and intraclonal 'Nellie White' selection by bulb growers results in different commercial strains within and among growers (Zlesak and Anderson, 2003 ). While only $18 \%$ of the variation is among growers, this significantly impacts greenhouse forcers, causing them to purchase from multiple growers. The Easter Lily Research Foundation could create an elite stock program, such as that developed for Pelargonium disease control (Wager-Page et al., 2006), that incorporates within- and among-bulb grower genetic variation to ensure crop viability and avoid potential genetic drift. A central propagator to source propagules to the lily bulb growers should also be created.

\section{Literature Cited}

Abe, H., M. Nakano, A. Nakatsuka, M. Nakayama, M. Koshioka, and M. Yamagishi. 2002. Genetic analysis of floral anthocyanin pigmentation traits in asiatic hybrid lily using molecular linkage maps. Theor. Appl. Genet. 105:1175-1182.

Anderson, N.O. 1986. The distribution of the genus Lilium with reference to its evolution. Herbertia 42:31-50.

Anderson, N.O. and P.D. Ascher. 1994. Clonal decline in horticultural crops due to Muller's ratchet. HortScience 29:435.

Anderson, N.O., A. Younis, and E. Opitz. 2009. Development of colored, non-vernalization-requiring seed-propagated lilies. Acta Hort. 836:193-198. 
Asano, Y. 1986. A numerical taxonomic study of the genus Lilium in Japan. J. Fac. Agr. Hokkaido Univ. 62:333-341.

Asano, Y. 1989. Lilium L., p. 198-209. In: Y. Tsukamoto (ed.). The grand dictionary of horticulture. Vol. 5. Syogakukan, Tokyo.

Beckman, J.S. and M. Soller. 1986. Restriction fragment length polymorphisms and genetic improvement of agricultural species. Euphytica 35:111-124.

Bennett, M.D., J.B. Smith, and J.S. Heslop-Harrison. 1982. Nuclear DNA amounts in angiosperms. Proc. R. Soc. Lond. B Biol. Sci. 216 : 179-199.

Booy, G., T.C.A.E. Wouters, and Y. Kleyn-Noorduk. 1998. Identification of lily cultivars using isoelectric focusing of proteins from bulb scales and tissue culture bulblets. Plant Breed. 117:57-62.

Buntjer, B.J. 1999. Software Crosscheck, Vol. 8. 12 July 2008. <http:// www.spg.wau.nl/pv/pub/CrossCheck/>.

Camacho, F.J. and A. Liston. 2001. Population structure and genetic diversity of Botrychium pumicola (Ophioglossaceae) based on intersimple sequence repeats (ISSR). Amer. J. Bot. 88:1065-1070.

Dai, T.E., W.L. Lee, and C.T. Shii. 2007. Genetic diversity and differentiation among native populations of Lilium formosanum and L. longiflorum of Taiwan based on molecular marker analysis. Acta Hort. 760:637-642.

Debener, T., C. Bartels, and L. Mattiesch. 1996. RAPD analysis of genetic variation between a group of rose cultivars and selected rose species. Mol. Breed. 2:321-327.

De Jong, P.C. 1974. Some notes on the evolution of lilies. North Amer. Lily Soc. Yrbk. 27:23-28.

Devarumath, R.M., S. Nandy, V. Rani, S. Marimuthu, N. Muraleedharan, and S.N. Raina. 2002. RAPD, ISSR and RFLP fingerprints as useful markers to evaluate genetic integrity of micropropagated plants of three diploid and triploid elite tea clones representing Camellia sinensis (China type) and C. assamica ssp. assamica (Assam-India type). Plant Cell Rep. 21:166-173.

Dole, J.M. and H.F. Wilkins. 2005. Floriculture principles and species. 2nd ed. Prentice Hall, Upper Saddle River, NJ.

Erwin, J.E. and G. Engelen-Eigles. 1998. Influence of simulated shipping and rooting temperature and production year on easter lily (Lilium longiflorum Thunb.) development. J. Amer. Soc. Hort. Sci. 123: 230-233.

Esselman, E.J., L. Jianqiang, D.J. Crawford, J.L. Winduss, and A.D. Wolfe. 1999. Clonal diversity in the rare Calamagrostis porteri ssp. insperata (Poaceae): Comparative results for allozymes and random amplified polymorphic DNA (RAPD) and inter-simple sequence repeat (ISSR) markers. Mol. Ecol. 8:443-451.

Fanelli, F.L. and A.A. De Hertogh. 2002. The effects of precooling temperatures and durations on forcing of Lilium longiflorum, 'Nellie White'. Acta Hort. 570:147-152.

Fay, M.F., R.S. Cowan, and I.J. Leitch. 2005. The effects of nuclear DNA content (C-value) on the quality and utility of AFLP fingerprints. Ann. Bot. (Lond.) 95:237-246.

Fisher, P.R. and J.H. Lieth. 2000. Variability in flower development of easter lily (Lilium longiflorum Thunb.): Model and decision-support system. Comput. Electron. Agr. 26:53-64.

Godwin, I.D., E.A.B. Aitken, and L.W. Smith. 1997. Application of inter-simple sequence repeat (ISSR) markers to plant genetics. Electrophoresis 18:1524-1528.

Gyulai, G., Z. Mester, J. Kiss, L. Szeman, A. Idnurm, and L. Heszky. 2003. Somaclonal breeding of reed canary grass (Phalaris arundinacea L). Grass Forage Sci. 58:210-214.

Hale, A.L., J.C. Miller, K. Renganayaki, A.K. Fritz, J.J. Coombs, L.M. Frank, and D.S. Douches. 2005. Suitability of AFLP and microsatellite marker analysis for discriminating intraclonal variants of the potato cultivar Russet Norkotah. J. Amer. Soc. Hort. Sci. 130:624-630.

Hancock, J.E., Jr. and R.S. Bringhurst. 1979. Ecological differentiation in perennial octaploid species of Fragaria. Amer. J. Bot. 66:367-375.

Hess, J., J.W. Kadereit, and P. Vargas. 2000. The colonization history of Olea europaea L. in Macronesia based on internal transcribed spacer 1 (ITS-1) sequences, randomly amplified polymorphic DNAs
(RAPD), and intersimple sequence repeats (ISSR). Mol. Ecol. 9:857868.

Lange, N. and R. Heins. 1990. The lowdown on how bulb size influences lily development. Grower Talks 53(10):52-54.

Lee, W.B., S.Y. Choi, and Y.S. Kim. 1993. An application of random amplified polymorphic DNA (RAPD) to systematics of some species of Lilium in Korea. Korean J. Plant Taxonomy 23:35-42.

Levinson, G. and G.A. Gutman. 1987. Slipped-strand mispairing: A major mechanism for DNA sequence evolution. Mol. Biol. Evol. 4:203-221.

Lim, K.B., J. Wennekes, J.H. de Jong, E. Jacobsen, and J.M. van Tuyl. 2001. Karyotype analysis of Lilium longiflorum and L. rubellum by chromosome banding and fluorescence in situ hybridization. Genome 44:911-918.

Liu, C.M., J.H. Xie, and W.H. Ma. 2007. Analysis of genetic relationships among mango germplasm using ISSR markers. Acta Hort. 763:185-190.

Mayes, S.G., M.A. McGinley, and C.R. Werth. 1998. Clonal population structure and genetic variation in sand-shinnery oak, Quercus havardii (Fagaceae). Amer. J. Bot. 85:1609-1617.

Michael Smith Laboratories. 2008. Primer sets. 1 Oct. 2008. <http:// www.michaelsmith.ubc.ca/services/NAPS/Primer_Sets/>.

Monte-Corvo, L., L. Goulão, and C. Oliveira. 2001. ISSR analysis of cultivars of pear and suitability of molecular markers for clone discrimination. J. Amer. Soc. Hort. Sci. 126:517-522.

Muller, H.J. 1964. The relation of recombination to mutational advance. Mutat. Res. 106:2-9.

Nei, M. 1972. Genetic distance between populations. Amer. Nat. 106:283-292.

Parks, J.C. and C.R. Werth. 1993. A study of spatial features in a population of bracken fern, Pteridium aquilinum (L). Kuhn. Amer. J. Bot. 80:1018-1025.

Peakall, R. and P.E. Smouse. 2009. 2006. GENALEX 6: Genetic analysis in Excel. Population genetic software for teaching and research. Mol. Ecol. Notes 6:288-295. <http://www.anu.edu.au/ $\mathrm{BoZo} / \mathrm{GenAlEx} />$.

Persson, H.A., K. Lundquist, and H. Nybom. 1998. RAPD analysis of genetic variation within and among populations of turk's-cap lily (Lilium martagon L.). Hereditas 128:213-220.

Pharmawati, M., Y. Guijun, and M.F. Patrick. 2005. Molecular variation and fingerprinting of Leucadendron cultivars (Proteaceae) by ISSR markers. Ann. Bot. (Lond.) 95:1163-1170.

Rani, V., A. Parida, and S.N. Raina. 1995. Random amplified polymorphic DNA (RAPD) markers for genetic analysis in micropropagated plants of Populus deltoids Marsh. Plant Cell Rep. 14:459-462.

Rani, V., A. Parida, and S.N. Raina. 2001. Chromosome number dependent genome size and RAPD fingerprinting diagnostics for genetic integrity of enhanced axillary branching-derived plants of ten forest tree species. Acta Hort. 560:531-534.

Rani, V., K. Singh, M. Shiran, S. Nandy, S. Goel, R.M. Devarumath, H.L. Sreenath, and S.N. Raina. 2000. Evidence for new nuclear and mitochondrial genome organizations among high frequency somatic embryogenesis-derived plants of allotetraploid Coffea arabica L. (Rubiaceae). Plant Cell Rep. 19:1013-1020.

Ridout, C.J. and P. Donini. 1999. Use of AFLP in cereals research. Trends Plant Sci. 4:76-79.

Roberts, A.N., J.R. Stang, Y.T. Wang, W.R. McCorkle, L.J. Riddle, and F.W. Moeller. 1968. Easter lily growth and development. Tech. Bul. No. 148, Oregon State Univ. Agr. Expt. Sta., Corvallis.

Roberts, A.N., Y.-T. Wang, and F.W. Moeller. 1983. Effects of preand postbloom temperature regimes on development on Lilium longiflorum Thunb. Sci. Hort. 18:363-379.

Rongwen, J., M.S. Akkaya, A.A. Bhagwat, U. Lavi, and P.B. Cregan. 1995. The use of microsatellite DNA markers for soybean genotype identification. Theor. Appl. Genet. 90:43-48.

Russell, F.S. and T.R. Rao. 1940. On habitat and association of species of anopheline larvae in south-eastern Madras. J. Malaria Inst. India 3:153-178. 
Sambrook, J., E.F. Fritsch, and T. Maniatis. 1989. Molecular cloning: A laboratory manual. 2nd ed. Cold Spring Harbor Laboratory Press, Cold Spring Harbor, NY.

Smyth, D.R., P. Kalitsis, J.L. Joseph, and J.W. Sentry. 1989. Plant retrotransposon from Lilium henryi is related to Ty3 of yeast and the gypsy group of Drosophila. Proc. Natl. Acad. Sci. USA 86:50155019.

Swoboda, I. and P.L. Bhalla. 1997. RAPD analysis of genetic variation in the australian fan flower, Scaevola. Genome 40:600-606.

Texas A\&M University. n.d. Easter lily. PLANTanswers publication. 16 June 2009. <http://aggie-horticulture.tamu.edu/plantanswers/ publications/lily/lily.html>.

Torres, A.M., T. Millan, and G.I. Gubero. 1993. Identifying rose cultivars using random amplified polymorphic DNA markers. HortScience 28:333-334.

U.S. Department of Agriculture. 2009. Floriculture crops 2008 summary, April 2009. 15 May 2009. <http://usda.mannlib.cornel1.edu/usda/current/FlorCrop/FlorCrop-04-23-2009.pdf $>$.

Veilleux, R.E. and A.A.T. Johnson. 1998. Somaclonal variation: Molecular analysis, transformation interaction, and utilization. Plant Breed. Rev. 16:229-268.

Vos, P., R. Hogers, M. Bleeker, M. Reijans, T. van de Lee, M. Hornes, A. Friters, J. Pot, J. Paleman, M. Kuiper, and M. Zabeau. 1995. AFLP: A new technique for DNA fingerprinting. Nucleic Acids Res. 23:4407-4414.

Wager-Page, S.A., V.S. Malik, and A.T. Tschanz. 2006. Basics of a proposed regulatory systems approach protocol: Plants for planting. 19 Feb. 2010. <http://www.aphis.usda.gov/import_export/plants/ plant_imports/downloads/q37_regulatory_sysapproach_protocol.pdf $>$. Wallner, E., K. Weising, R. Rompf, G. Kahl, and B. Kopp. 1996. Oligonucleotide and RAPD analysis of Achillea species: Characterization and long-term monitoring of micropropagated clones. Plant Cell Rep. 15:647-652.

Wang, G., R. Mahalingam, and H.T. Knap. 1998. (C-A) and (G-A) anchored simple sequence repeats (ASSRs) generated polymorphism in soybean, Glycine $\max (\mathrm{L})$. Merr. Theor. Appl. Genet. 96:10861096.

Wang, J., L. Huang, M. Bao, and G. Liu. 2009. Production of interspecific hybrids between Lilium longiflorum and L. lophophorum var. linearifolium via ovule culture at early stage. Euphytica 167: 45-55.

Ward, S.M., S.D. Reid, J. Harrington, J. Sutton, and K.G. Beck. 2008. Genetic variation in invasive populations of yellow toadflax
(Linaria vulgaris) in the western United States. Weed Sci. 56: 394-399.

Wen, C.S. and J.Y. Hsiao. 2001. Altitudinal genetic differentiation and diversity of Taiwan lily (Lilium longiflorum var. formosanum; Liliaceae) using RAPD markers and morphological characters. Intl. J. Plant Sci. 162:287-295.

Wilkins, H.F. and S.M. Roh. 1976. Even higher flower bud numbers are now possible in easter lilies by dipping your greenhouse temperature. Minnesota State Florists Bul. Dec.:8-12.

Williams, J.G.K., A.R. Kubelik, K.J. Livak, J.A. Rafalsi, and S.V. Tingey. 1990. DNA polymorphisms amplified by arbitrary primers are useful as genetic markers. Nucleic Acids Res. 18:6531-6535.

Wolfe, A.D., Q. Xiang, and S.R. Kephart. 1998. Diploid hybrid speciation in Penstemon (Scrophulariaceae). Proc. Natl. Acad. Sci. USA 95:5112-5115.

Wolff, K., E. Zietkiewicz, and H. Hofstra. 1995. Identification of chrysanthemum cultivars and stability of DNA fingerprint patterns. Theor. Appl. Genet. 91:439-447.

Wu, K.S. and S.D. Tanksley. 1993. Abundance, polymorphisms and genetic mapping of microsatellites in rice. Mol. Gen. Genet. 241: 225-235.

Yamagishi, M. 1995. Detection of section-specific random amplified polymorphic DNA (RAPD) markers in Lilium. Theor. Appl. Genet. 91:830-835.

Yamagishi, M., A. Hiromi, N. Michiharu, and N. Akira. 2002. PCRbased molecular markers in asiatic hybrid lily. Sci. Hort. 96:225234.

Zietkiewicz, E., A. Rafalski, and D. Labuda. 1994. Genome fingerprinting by simple sequence repeat (SSR)-anchored polymerase chain reaction amplification. Genomics 20:176-183.

Zlesak, D., J. Bradeen, and N.O. Anderson. 2007. The use of AFLP markers to resolve clonal origin and integrity in rose, hydrangea, and lily. Floriculture Ornamental Biotechnol. 1:51-60.

Zlesak, D.C. 2006. Genetic components of white trumpet lilies: Clonal variation in Lilium longiflorum Thunb. 'Nellie White' and inheritance of non-obligate vernalization for stem elongation and flowering in L. formosanum Wallace. Ph.D. Diss., Univ. Minnesota, St. Paul.

Zlesak, D.C. and N.O. Anderson. 2003. Inside West-coast easter lily production. North Amer. Lily Soc. Quarterly 57:12-16.

Zlesak, D.C. and N.O. Anderson. 2007. Clonal variability among grower bulb lots of easter lily 'Nellie White'. J. Amer. Soc. Hort. Sci. 132:29-43. 